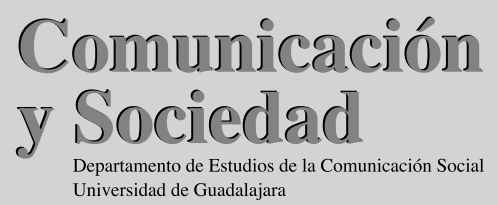

\title{
Discusiones teóricas y metodológicas sobre el estudio del discurso desde el campo de la comunicación
}

\author{
MYRIAM REBECA PÉREZ DANIEL ${ }^{1}$
}

A partir de la clarificación teóricametodológica del fenómeno discursivo propuesto por Roland Barthes, es posible ubicar su estudio en el campo de la comunicación y no ya en los dominios de la lingüística. El discurso, según Barthes, no refiere a un texto que construye un sentido, sino al sentido socialmente creado $\mathrm{y}$ compartido que atraviesa a los textos. Por tanto, su análisis no debe recaer en la comprensión del texto, sino en la comprensión de los sujetos que se comunican a través de él.

PALABRAS CLAVE: discurso, análisis del discurso, campo de la comunicación, estructuralismo, semiología.
From the theoretical-methodologic clarification of the discourse phenomenon proposed by Roland Barthes, it is possible to locate its study in the field of the communication and not in the dominions of the linguistic. The discourse, according to Barthes, does not refer to a text that a sense constructs, but the sense socially created and shared that it crosses to texts. Therefore, their analysis does not have to fall to the understanding of the text, but to the understanding of the subjects that communicate through him.

KEY WORDS: discourse, analysis of discourse, field of communication, structuralism, semiology.

1 Universidad Autónoma de Chiapas.

Correo electrónico: rebecaperezdaniel@yahoo.com.mx 
"No podemos entrar en el no discurso porque el no discurso no existe".

Roland Barthes

\section{LA UBICACIÓN DEL ESTUDIO DEL DISCURSO}

EN EL CAMPO DE LA COMUNICACIÓN:

HACIA EL INTERÉS POR LO SOCIOCULTURAL

La ubicación del fenómeno del discurso en un campo de estudio en particular resulta difícil. Por una parte, el discurso se suele asumir como un objeto propio de la lingüística, puesto que su estudio se asocia a la decodificación de un contenido tal implicado en él, sólo accesible por la vía de la lectura atenta del uso que hace de la lengua. Por otra parte, la ubicación de su investigación en un campo de estudio suele depender de qué tipo de saber se implica en el contenido del discurso a estudiar. Si resulta un contenido propio de la educación, esta lo ampara bajo el campo de fenómenos que le atañe. Si resulta que su contenido refiere aspectos políticos, lo político lo ampara bajo el conjunto de fenómenos que le son de su interés.

Así pues, el discurso pareciera resultar un fenómeno amorfo y maleable acorde al tipo de contenido que expresa, de indudable parentesco lingüístico pero migrante hacia cualquier disciplina que haga suyo el interés por su análisis. Es decir, pareciera que el discurso no tiene, por sí mismo, un nicho de estudio fijo y permanente, ni tampoco una naturaleza clara, de tal forma que se haga patente su pertenencia a cierta disciplina. Por ello, también, el estudio del discurso aparece con frecuencia en cualquier campo de las ciencias sociales, más en calidad instrumental del análisis de datos, que como reflexión constitutiva de un tipo de fenómeno, cuyo sustento teórico metodológico le permita existencia propia, más allá del interés que cierto campo pueda tener de su contenido.

En resumen, el discurso aparece, entonces, como un fenómeno de fácil acceso cuyo estudio consiste en su descomposición lingüística, denotando con esto un contenido que puede ser de interés para cualquier campo. La dificultad para ubicar su naturaleza y pertenencia a un 
campo de estudio, sin embargo, no se debe a esta imagen estereotipada del discurso, sino a lo que implica tener en las ciencias sociales, una imagen estereotipada de un fenómeno².

La primera implicación de este estereotipo es que existe un gran número de objetos de diversa índole y composición que suelen cubrirse con el nombre de "discurso". Por ejemplo, Van Dijk (2003) asume que "discurso" equivale a "texto", asunción que no comparte Roland Barthes (2001), para quien "discurso" es distinto a "texto". Este juego de distinciones y/o sinónimos resulta crucial para definir la naturaleza del fenómeno "discurso" y el objeto de su análisis.

Si "discurso" se ha de asumir como "texto" y el análisis como la decodificación de una serie de posicionamientos del autor con respecto a un tema, a la usanza de Van Dijk (2003), el análisis de discurso se convierte en un estudio del contenido de cualquier producción textual, donde interesa cómo $x$ autor habla de $x$ cosa. No así desde Barthes, para quien el fenómeno del "discurso" rebasa todo texto. Un conjunto de textos puede denotar la existencia de un "discurso", mas nunca abarcarlo todo, puesto que el discurso, para Barthes (2001), es más un fenómeno de construcción social que de posicionamiento autorial. Así, para el semiólogo francés el estudio del discurso tiene sentido en la comprensión de la imaginería ${ }^{3}$ que cierta sociedad produce sobre $x$ cosa

2 Nacida, claro, de la experiencia práctica de los investigadores sociales que hacen uso de ella. El análisis del discurso posee la cualidad de enfrentar a sus estudiosos a un doble filo: el lingüístico y el social. La tendencia a decantarse por uno de ellos hace todavía más sentida la imagen ambigua del análisis discursivo e, incluso, favorece esta estereotipación del análisis como herramienta auxiliar de cualquier estudio.

3 "Imaginería" refiere a una doble característica del acervo común de sentidos creado socialmente en torno a un tema. Implica, por una parte, el carácter imaginario (casi ficticio) de los sentidos socialmente creados y compartidos con respecto a un tema. Dicha construcción ficticia no implica una oposición con lo real. Es real para los sujetos en cuanto a que actúan con respecto a esa construcción, pero el material del que está hecho es abstracto, imaginario, pues. Por otro lado implica, también, una metáfora de esos imaginarios con las imágenes, composiciones iconográficas que encierran un sentido 
en cierto momento histórico, y no tanto en lo que dice una producción textual aislada. Para Barthes (2001), el texto es la primera puerta para acceder al discurso, nunca la mira de todo el análisis.

Lo que se ha de entender por "discurso", pues, ha de determinar la naturaleza del fenómeno del que se habla y su pertenencia a cierto campo. Si hay distintas definiciones sobre lo que es discurso, se debe entender, entonces, que hay distintos fenómenos en construcción. Decir exactamente qué se entiende por discurso es ya promover la ubicación.

Otra implicación del estereotipo que carga el estudio del discurso y que impone una dificultad para su ubicación disciplinar, es la tendencia a asociarlo a la decodificación de un contenido. Por ello, por ejemplo, al iniciar este capítulo se mencionaba la tendencia a ubicar el campo disciplinar del análisis discursivo acorde al tema a tratar. Sin embargo, esta tendencia no considera la complejidad del fenómeno discursivo visto, por ejemplo, desde la visión barthesiana.

Para comprender esta complejidad es necesario partir de la teoría de la enunciación. Esta, como lo explica bien Verón (1999) en su intento por comprender a Barthes, parte de distinguir entre dos niveles de funcionamiento del fenómeno comunicativo: el plano de la enunciación y el del enunciado. Estos dos niveles son diferentes y están necesariamente presentes en todo acto comunicativo, sea este lingüístico o no. El plano del enunciado es aquel que corresponde al contenido. El plano de la enunciación es, en palabras de Veron, "aquel en el cual, en el discurso mismo, se construyen las posiciones del que comunica (enunciador) y de aquel a quien el acto de discurso está dirigido (destinatario)" (1999:95).

complejo pero condensado en su representación sobre algo. La imagen de un árbol, por ejemplo, en su representación condensa lo que sabemos de él: las partes que lo componen, su proceso de vida, sus funciones vitales, sus características biológicas, etc. La metáfora refiere a esas condensaciones de saberes condensados en un sentido, no tanto a la representación gráfica. Este es el doble sentido que la palabra "imaginería" encierra para Barthes (2005) y que se asociarán a él cuando se mencione el término. Queden, por tanto, excluidos sentidos tales como imaginario colectivo o representación social provenientes de otras teorías sociales. 
El fenómeno discursivo barthesiano está al nivel de la enunciación, puesto que el acervo común de sentidos construidos y compartidos socialmente sobre un tema está hecho, según Barthes (2001, 2005), de codificaciones de la forma de decir las cosas y no de la codificación de las cosas que se dicen en sí. Así, la imaginería que descubre el discurso barthesiano se ve conformado por formas, lugares comunes, estereotipos de las formas del habla, trazos, posicionamientos, etcétera, todo lo vinculado a las maneras de decir algo, no a los contenidos.

Por otro lado, el fenómeno discursivo de Van Dijk (2003) sí está enfocado a los contenidos, puesto que está hecho de enunciados, planteados a nivel lingüístico, construidos en distintas capas de significación las cuales aprisionan el contenido a liberar. En este tipo de análisis toma crucial importancia el quién dice qué y en qué condiciones, no tanto el cómo (aunque también lo consideran, pero como parte de entender el qué). La teoría discursiva de Van Dijk, entonces, podría decirse, se ubica a nivel de enunciado 4 . La teoría discursiva barthesiana se ubica, en cambio, a nivel de enunciación, donde el énfasis está en el cómo, porque es el que se construye, codifica y comparte socialmente según este autor 5 . Quede claro, entonces, que la diferencia de posicionamiento cambia por completo la composición del fenómeno y las prioridades de búsqueda.

La última implicación del estereotipo asociado al estudio del discurso, es el supuesto de que toda vía lingüística es ya una vía para el análisis discursivo, puesto que el discurso es de naturaleza lingüística.

4 Es justo mencionar que la teoría discursiva de Van Dijk se encuentra a nivel del enunciado por su inquietud de denunciar los contenidos ideológicos manifiestos a ese nivel, siguiendo una tradición marxista. Su objetivo no es la comprensión del discurso en sí, sino la comprensión del discurso como herramienta ideológica de cierta clase social, en un contexto social determinado.

5 Interesado, enteramente, en la composición discursiva en sí, como vía de acceso a la comprensión de la composición social y cultural de una determinada sociedad usuaria y productora del discurso. La diferencia de objetivos de estudio entre Barthes y Van Dijk determina los porqués de las diferencias de sus concepciones de discurso. El punto, de igual manera, es hacer notar que las diferencias son muchas, pese a que se hable del fenómeno discursivo. 
Así lo asume Van Dijk (2003), por ejemplo, pero precisamente porque parte de asumir al discurso como compuesto por enunciados, en donde el qué se dice resulta crucial. Por ello propone una lista larga de marcadores discursivos que van desde el uso del léxico hasta la construcción argumentativa a través de la cohesión y la coherencia, los tipos textuales, las implicaciones, las omisiones, los temas, la voz activa, la vinculación contextual, la presencia de modelos y los indicadores ideológicos. Todos estos utilizados para el análisis, en el supuesto de que el texto posee capas le lectura que se han de develar con cada categoría agregada. Van Dijk (2003) advierte que es posible agregar más categorías, tantas como sea necesario, buscando con ello los sentidos del contenido detrás del texto.

Barthes (2001), en cambio, centra su atención en una serie corta de procedimientos maleables, pero rigurosos, que pretenden esclarecer la composición del discurso, en cuanto a fenómeno hecho de enunciaciones, en elementos tales como las tópicas y las figuras, categorías no necesariamente lingüísticas, sino semiológicas, aunque sí con procedimientos de corte lingüístico. Resultan semiológicas puesto que el nivel de la enunciación está presente en comunicaciones lingüísticas y no lingüísticas (Veron, 1999), es decir, están a nivel comunicacional. El énfasis del análisis, por tanto, no está en las categorías lingüísticas en sí, sino en las categorías semiológicas a las que, ciertamente, se pueden acceder por vía lingüística. En todo caso, el uso instrumental de elementos lingüísticos no inscribe forzosamente al discurso en la disciplina lingüística, sino en la disciplina que echa mano de ellas. Dicha disciplina, como ya decía Saussure (1982), es la semiología.

Al fin, pues, la imagen estereotipada del discurso promovida en las ciencias sociales le ha negado una ubicación en un campo determinado desde una disciplina determinada, es decir, le ha negado el estatus de objeto y lo ha limitado, en diversas prácticas investigativas, a un simple instrumental analítico6 ${ }^{6}$ Mi intención, en este trabajo, no es reivindi-

6 Claro que es posible ver esta negación de ubicación como algo positivo e incluso deseable para el análisis del discurso. En realidad, su desubicación le ha permitido enriquecerse de los intereses, metodologías y teorías de múltiples disciplinas (como la historia, la psicología, la sociología, la 
car al discurso ante su estereotipo, pero sí exponer un sustento teórico metodológico particular y concreto que permita visualizar al discurso, entendido a partir de las reflexiones barthesianas, como un fenómeno de estudio accesible desde la disciplina semiológica, en el campo de la comunicación.

Exponer, pues, un objeto de estudio del campo de la comunicación inspirado en las reflexiones teórico metodológicas de Roland Barthes y ubicadas desde la disciplina semiológica. No el discurso como objeto amorfo y flexible, sino entendido desde los supuestos barthesianos y ubicado en las coordenadas que a continuación explico.

El discurso de corte barthesiano es un fenómeno del campo de la comunicación, puesto que captura en él la imaginería compartida y creada socialmente en torno a un tema. Esta imaginería no sólo ayuda a entender cómo se concibe cierto objeto en la vida cotidiana, sino la línea lógica que dicta cómo comportarse con respecto a dicho objeto7. Así, el discurso se vuelve un repertorio de imágenes constituidas como "unidades de sentido"8 que dan, precisamente, sentido al decir y al hacer común sobre un objeto. Dicho repertorio se actualiza en los textos, convirtiendo a los sujetos no sólo en usuarios, sino en productores de esas imágenes compartidas.

El discurso, entonces, se convierte en un repertorio de posibilidades de acceso común para referirse a un objeto. Al hablar o actuar sobre dicho objeto se hace a partir de alguna referencia a ese repertorio, puesto que este es el acervo común para referirse a aquel. Sin ese repertorio de carácter común, la comunicación y el entendimiento mutuo no serían posibles. Es, pues, el discurso parte de la comunicación cotidiana y de los relieves de sentido que conforman el panorama cultural.

antropología, etcétera), mientras que, a la vez, impregna, con sus propios intereses, metodologías e intereses, a esas mismas disciplinas.

7 Puesto que está hecho de formas de decir algo. Las formas sugieren formas de posicionarse ante ese algo y, por tanto, formas de vincularse con él.

8 Las unidades de sentido implican un núcleo condensado de sentidos referidos a un tema, estructurados y socialmente compartidos de tal forma que permiten ser comunicados. 
Al señalar la pertenencia de este fenómeno al campo de la comunicación, se parte de concebir dicho campo como aquel compuesto por los fenómenos referentes a la interacción social. Este sentido de la Comunicación ciertamente es ambiguo, pero es el sentido más aceptado en los ámbitos académicos dedicados al estudio de la comunicación, según el analista Raúl Fuentes (2000), quien hace notar que la tendencia académica del campo, en la actualidad, es a aceptar nociones más amplias del fenómeno comunicativo para ganar claridad en cuanto a recursos teórico metodológicos disponibles para pensar, también, los "cimientos conceptuales" de la producción de conocimiento referente a lo "comunicacional".

Fuentes (idem) admite que la constitución teórica del fenómeno comunicacional es un problema irresuelto, más aún con el constante incremento de perspectivas y fenómenos que se investigan a partir del campo. Sin embargo, apuntala hacia la construcción de un marco de interpretación que integre conceptual y metodológicamente lo político, lo cultural y lo existencial desde los agentes comunicacionales mismos, como la vía para unificar el campo. Es decir, propone entender lo comunicacional como elemento constitutivo, y no accesorio, del actuar de los sujetos, actuar que conlleva a trazar lo existencial, lo político y lo cultural. Así, lo comunicacional no sería aquello que vincula, afecta o modifica el panorama social, sino lo que lo produce y le da consistencia.

La apuesta de Fuentes (idem), pues, es centralizar el estudio de la comunicación en el actuar de los sujetos. Con ello, la preocupación del campo de la comunicación recaerá en tres elementos a atender: el estudio de la vida cotidiana, el estudio de las competencias discursivas de los sujetos y el estudio de las identidades generadas a partir de las otras dos. Si bien Fuentes ubica el asunto del discurso y la competencia de la semiología en ello, en la atención al segundo elemento, el énfasis que le da no es tanto en la comprensión del discurso en sí, sino del uso que hacen de él los sujetos.

El proyecto de Roland Barthes (2005) es distinto. Si bien el estudio del discurso que él propone parte también de las prácticas de los sujetos, la mira no está en comprender el uso que le dan estos al discurso. Eso sería un interés sociológico, según Barthes. Más bien, la preocupación 
de este es dar cuenta de los sentidos que el discurso evidencia, pues así se enfatiza el funcionamiento de la comunicación, de la acción y, ahora sí, el uso que hacen los sujetos del discurso. ${ }^{9}$

Ciertamente, el proyecto de Barthes no se adscribe del todo en la mira de Fuentes (2000) para el campo de la comunicación, más cuando este declara su inclinación por la propuesta sociológica de la teoría de estructuración de Anthony Giddens para el logro de la unificación del campo. Sin embargo, Barthes puede abonar a este proyecto, puesto que, en todo caso, la apuesta de ambos sigue siendo partir de la agencia del sujeto como productor y usuario del sentido socialmente compartido.

Corona (2000) también vislumbra esta apuesta por el sujeto como propia del campo de la comunicación y del futuro de los estudios gestados en él. Corona, sin embargo, ubica otro elemento a atender, además de la vida cotidiana y la competencia discursiva de los sujetos, para explorar a los sujetos productores. Ella, pues, hace énfasis no tanto en la identidad desarrollada por el sujeto a partir de sus prácticas comunicativas, sino en el ejercicio del poder que acarrea la identidad impuesta por los otros sujetos, en sus prácticas cotidianas y discursivas con respecto a un sujeto particular. A estas prácticas de imposición de identidad son las que ella ubica como prácticas sociales públicas y privadas, y llama la atención hacia ellas para estudiarlas. Corona (idem), entonces, ubica su prioridad de estudio en este último rubro, todo dentro del campo de la comunicación.

Tanto para Fuentes (2000) como para Corona (2000), el discurso, entendido como una práctica humana de creación de sentido se conforma como un elemento crucial en la comprensión de la actividad humana que gesta la vida cotidiana, la identidad y las relaciones de poder. El discurso se produce y usa en la cotidianidad. El discurso identifica. El discurso distingue. Acorde a estos expertos, el interés que el campo

9 El sujeto, en la teoría barthesiana, no es el punto de inicio para la comprensión del discurso, pero sí el punto final, donde el discurso en sí, su constitución y reglas de funcionamiento, tiene sentido. El sujeto no se supedita pasivamente al discurso, pero sí es atravesado y moldeado por él en una relación interactiva y compleja, misma que es abordada por Barthes a través del estudio de los códigos discursivos. 
de la comunicación tiene con respecto al discurso como fenómeno, es el de comprender cómo es producido por los sujetos, cómo es usado por los sujetos y cómo es que su producción y uso crean un sentido de carácter social.

En esta comprensión del campo de la comunicación y del papel del estudio del discurso en él, es con el que se identifica este entramado teórico metodológico. Se asume, pues, al campo de la comunicación como un espacio de estudio conformado por el interés de producir conocimiento sobre la interacción social misma, cuyo énfasis ponen el aspecto de la cotidianidad, la discursividad, el poder y la identidad.

También se parte de la centralidad de los sujetos como productores y usuarios de sentidos, sentidos latentes no sólo en los discursos, sino en los mecanismos de producción discursiva y en los mecanismos de uso discursivo. Aún cuando Barthes, teórico inspirador de este posicionamiento teórico metodológico, esté interesado más en los imaginarios contenidos en esos discursos, dichos imaginarios, al fin, hablarán del uso y la producción del sentido del discurso. Barthes, pues, antepone la prioridad del imaginario ante el sujeto, no porque este se supedite a aquel, sino porque cree que sólo comprendiendo el imaginario se comprenderá al sujeto ${ }^{10}$. Este, pues, sigue siendo central.

Recapitulando, entonces, Fuentes (2000) y Corona (2000) admiten la imperiosa necesidad de recurrir al estudio del discurso para comprender los fenómenos comunicativos. Ellos, sin embargo, han apostado por estudios distintos para llegar a esta comprensión, sin dejar de señalar la presencia y la importancia del discurso en la constitución del campo. Fuentes ha partido desde el estudio de los sujetos como agentes comunicativos. Por su parte, Corona ha optado por el estudio de las prácticas discursivas de los sujetos en relación con su contexto. La mira en ambos está en afianzar el campo comunicativo concibiendo la comunicación en un sentido que se enclava en la actividad de los sujetos y su capacidad para producir sentido. La apuesta de esta perspectiva, en particular, es unirse a ese mismo fin, pero por la vía del discurso, como objeto de la comunicación.

$10 \quad$ Ver nota 9. 


\section{EL ESTRUCTURALISMO}

COMO POSICIÓN EPISTEMOLÓGICA

En afán de seguir aclarando el posicionamiento de este marco teórico metodológico para asumir y estudiar el discurso, vale de nuevo insistir en que este trabajo está inspirado por las reflexiones de Roland Barthes. Cabe, entonces, mencionar que este, como productor de conocimiento, se ubicó y autoasignó como parte del movimiento estructuralista11. Según él, ser estructuralista implicaba un posicionamiento de pensamiento y análisis tal preocupado por encontrar, por medio de procedimientos rigurosos y precisos, "la estructura de los objetos sociales, de las imágenes culturales y los estereotipos"12 (2005:53).

De nuevo, entonces, se hace presente el énfasis que Barthes da a la composición del discurso y a su funcionamiento en sí sobre los contextos de producción o uso de este, no porque la producción y uso no tengan importancia, sino porque parte de la creencia de que la estructura del discurso y los mecanismos que lo hacen funcionar bastan para comprender los contextos de producción y actualización de dicho dis-

11 Del Barthes autoasignado estructuralista es del que se toman las referencias teóricas para construir el posicionamiento aquí descrito. Cabe mencionar que Barthes mismo se fue distanciando de la etiqueta estructuralista (mas nunca del todo de sus principios), por encontrarla algo estorbosa para el tipo de trabajos que después pretendió. Mostró, muchas veces, su disgusto por encasillar todo su trabajo bajo un tipo de clasificación específica, pero no llegó a negar nunca sus intenciones con respecto al proyecto semiológico que tenía en mente, proyecto inscrito en los principios estructuralistas.

12 Entendiendo a los estereotipos no como un tipo de imagen o idea única aceptada por un grupo o sociedad con carácter inmutable. Esto haría creer que socialmente hay formas únicas de entender un tema y que son inmodificables. Pero la concepción de Barthes no es así. Más bien se apega a entender el estereotipo como repeticiones intempestivas de uno o varios gestos discursivos, que sí dan evidencia de una imagen aceptada socialmente, pero tan mutable como cualquier otro lugar común. Entiéndase, entonces, de esa forma el sentido de estereotipo que se mencionará a lo largo del texto. 
curso'13. Como el nombre mismo de estructuralismo puede inspirar, la primacía de la estructura sobre el dinamismo o el sujeto reina bajo la apuesta de que la primera basta para la comprensión de los segundos.

Barthes (2005) partía de la siguiente reflexión: todos los objetos que son motivo de algún discurso en la realidad actual cumplen una función precisa, vinculada casi siempre a la comunicación. Son, pues, vehículos de significación. La apuesta, entonces, debe ser el estudio de la estructura de esos objetos, puesto que sólo la estructura indicará cómo es que están conformados, cómo funcionan, para qué y en qué condiciones fueron creados y cómo y para qué los usan los sujetos que lo producen y los usan. La estructura del discurso es el camino hacia el sujeto social; sólo a través de ella se puede comprender lo humano.

Estos presupuestos estructuralistas nacen, ciertamente, de la escuela lingüística, pero el movimiento en el que participó Barthes incitaba a extender su aplicación al territorio de otras disciplinas. Barthes (idem) aseguraba que el estudio de las estructuras discursivas debía ser propio de la disciplina semiológica trazada por Saussure. Los Mattelart (1997) también ubican a este dentro del panorama histórico de las teorías de comunicación como el iniciador del estructuralismo.

Saussure (1982) ubicó, por su parte, a la semiología como parte de la psicología social y no de la lingüística, y le asignó la tarea del estudio del signo y su relación con el seno social que lo alimenta. Por ello contempla en la semiología el estudio de la lengua, término que define como un sistema semiótico o de signos similar a otros, todos ellos utilizados para significar, pero de los cuales el lenguaje es siempre el más importante. La naturaleza semiológica del lenguaje, es decir, su capacidad para significar, proviene de su carácter convencional. El lenguaje es, pues, una institución social. Sólo su carácter colectivo o social hace del lenguaje o de cualquier signo un hecho semiológico: si no es social o colectivo un fenómeno sígnico no es semiológico.

13 Si es necesario, baste recordar que la teoría barthesiana se ubica a nivel de la enunciación, es decir, al de las formas del decir. Comprendiendo cómo es que se usan esas formas en las prácticas discursivas cotidianas, dice Barthes, se podrá dilucidar, no sólo el qué se dice, sino el para qué, es decir, el vínculo entre el qué se dice y el contexto. 
Así, hacer semiótica para Ferdinand de Saussure (idem) significa hacer explícito el funcionamiento social de los sistemas semióticos, explicar cómo es que esos sistemas producen la significación. Es, pues, el estudio de los signos y su gramática. Barthes (2005) entiende esta semiología saussureana y la presenta como una ciencia modelo para el estructuralismo. La semiología, según Barthes, debe, entonces

aplicar los conceptos y las reglas de descripción de la lingüística a colecciones de objetos que ya no son lenguaje articulado, y someter esas colecciones a un análisis que podría ser el que se le aplica a una lengua cuando se quiere conocer su gramática (2005:54).

Barhtes, entonces, hace suyo el proyecto estructuralista saussureano, sin embargo, lleva a la semiología un poco más allá, y la ubica dentro del interés y del campo de la comunicación. Todo lo que en los lenguajes refiere a la significación y a la connotación, es decir, todo aquel proceso social por el cual se asigna un sentido a un significante y todo aquel proceso social por el cual se vincula una ideología a un significado, debe ser de interés comunicacional. Estos elementos, la significación y la connotación, crean un sistema de sentido que subyace al de las apariencias del decir, y son estos elementos, pues, los que deberían ser motivo de estudio de los analistas comunicativos.

Por ello, Barthes (Mattelart y Mattelart, 1997) participa, en 1960, de la creación del Centro de Estudios de las Comunicaciones de Masas (CECMAS). Este centro, en el que participaron Friedmann y Morin también, se propuso el estudio de las relaciones entre la sociedad y las comunicaciones de masas como objetivo rector, sin insistir en un posicionamiento epistemológico uniforme. Sólo Barthes, entonces, se siguió situando bajo el cobijo del estructuralismo. Su proyecto de investigación personal siguió siendo desarrollar "una verdadera ciencia de la cultura" que fuera de inspiración semiológica (Mattelart y Mattelart, 1997:61). Sus trabajos más reconocidos, Mitologías (1980) y El sistema de la moda (1990), intentaron cumplir esta función. Estos y el resto de su obra dejan trazos de este proyecto que aún se requiere desarrollar.

Así, en este artículo se intenta promover la continuación del proyecto barthesiano a la luz de sus logros, pero, aún más, se aspira a sustentar 
un posicionamiento riguroso y fundado ante los fenómenos discursivos, con el ánimo de aportar en el conocimiento de su estructura y recalcar el impacto de esta en la vida de los sujetos. Por tanto, este trabajo sigue creyendo en el amparo estructuralista.

Desde este estructuralismo, se ha de suponer un esquema de la comunicación distinto al tradicional, el cual implica un emisor, un mensaje y un receptor. El esquema estructuralista del discurso, en cambio, supone que el fenómeno de la comunicación se lleva a otro nivel más difícilmente identificable que los sujetos productores y receptores. El discurso es, pues, un fenómeno estructural, un conjunto de sentidos creados socialmente a manera de repertorio comunicacional. Los sujetos, al hablar o escribir, no producen el discurso, sino que hacen uso de él y lo actualizan, modificándolo siempre y avivándolo, pero con una constante previa que es de dominio común. Los sujetos, al escuchar o al leer, no reciben el discurso como si lo hubiesen encontrado de pronto e inesperadamente, sino que lo comprenden a partir del repertorio discursivo que poseen.

El impacto del discurso en la vida de los sujetos, pues, no es momentáneo ni espontáneo, ni perceptible e identificable en momento y espacio determinado. El discurso es un fenómeno encarnado en la misma formación social que tenemos sobre las cosas del mundo. Así de dominado y desconocido, viejo y nuevo, es el discurso para los sujetos. El discurso, entonces, es un fenómeno que rebasa a los sujetos emisores y receptores. Es un fenómeno que se enclava, más bien, en las honduras del panorama cultural, en los imaginarios socialmente compartidos.

El estudio estructural del discurso propone entender su conformación y funcionamiento, porque en esa conformación y funcionamiento están las reglas para su renovación, actualización, uso social y aplicación a la vida cotidiana que pueden hacer los sujetos. Por ello, pues, sólo a través de la estructura se puede llegar a los sujetos. Esa es la propuesta estructuralista de este fenómeno comunicacional, y desde aquí se posiciona el argumento de este trabajo.

\section{LA SEMIOLOGÍA BARTHESIANA}

La semiología que ampara esta propuesta es el tipo de semiología que Barthes trazó en sus trabajos de investigación, y que difiere un poco del 
tipo de semiología que Saussure (1982) creó. Para apreciar, entonces, dicha diferencia, es necesario partir de la explicación de la semiología saussureana, que se basa en la teoría del signo y que distingue una serie de elementos, expuestos a continuación, que determinan el posicionamiento de Saussure.

- Significante y significado: este refiere al sentido socialmente asignado a aquel. El significante refiere al objeto, sonido o imagen vinculada a un significado. Significado y significante, asociados, conforman al signo. Este, entonces, es todo aquel objeto, sonido o imagen vinculada socialmente a un sentido. Es decir, el signo es convencional y arbitrario.

- Lengua y habla: Saussure (idem) definió a la lengua como el idioma en sí, el estático y sin evolución, mientras que el habla es el idioma hablado, sujeto a la regla suprema del uso, es decir, al principio que dicta que la lengua no existe en sí, sino en el uso que se hace de ella.

- Sincronía y diacronía: la primera estudia momentos estáticos de la lengua; la segunda el dinamismo del habla (Pérez Martínez, 2000).

- Paradigma y sintagma: el primero constituye el sistema de posibilidades de significación que un sujeto tiene para investir el signo. Sintagma es la elección hecha por el sujeto.

La propuesta semiológica de Saussure (1982) consiste en entender a la cultura como un sistema de posibilidades de interpretación (paradigmas culturales) que se evocan en el sintagma, en la selección de una práctica concreta de significación. Los sujetos, los que eligen dentro del paradigma de significación, ciertamente son los que permiten la diacronía y generan el habla, son los que crean la lengua y modifican las reglas de esta. En ello radica la arbitrariedad del signo. Pero sólo se puede entender ese dinamismo a partir del estudio de lo estático, es decir, de la lengua, de la sincronía y el paradigma.

La apuesta de Saussure (idem) se inclina, entonces, a preferir el estudio de la lengua sobre el habla, de la sincronía sobre la diacronía y del paradigma sobre el sintagma, puesto que el dinamismo de las segundas impide asir alguna pista en la comprensión de los signos. Simplemente, pues, para Saussure es imposible abordar el habla, puesto que no imaginó camino metodológico posible que permitiera asir sus transforma- 
ciones, aun cuando reconociera que el habla es lo más determinante en la comprensión del funcionamiento del código.

La propuesta de Barthes (2005), en cambio, es en esto distinta. Para él, la mira está también en reconstruir el paradigma, la lengua y la sincronía, a diferencia de Saussure (1982); Barthes creía que sólo el habla, lo diacrónico y el sintagma podrían dar acceso a esas estructuras fijas. Pareciera que hay una contradicción con lo ya dicho sobre Barthes, sin embargo, su interés por la estructura sobre el sujeto, para llegar a la comprensión del sujeto, está a nivel teórico. A nivel metodológico, la única forma que Barthes (2005) encontró para acceder a la estructura, y de ahí a la comprensión del sujeto, es este mismo, es decir, partir de lo que dice, elige, usa a diario. El discurso, pues, actualizado por el sujeto.

La diferencia central, entonces, de la semiología barthesiana con respecto de la saussureana es el camino metodológico que ambos eligieron para estudiar y comprender el funcionamiento de los códigos culturales de creación de sentido. Mientras Saussure (1982) apostó por la vía de lo estático para comprender lo estático, Barthes (2005) optó por la de lo dinámico para asir lo estático y comprender aquel a la vez. Esa es la semiología barthesiana.

Barthes (2005), por otra parte, imaginó aplicar esta búsqueda de las estructura de sentido en otros sistemas de signos diferentes a la lengua; diferentes esencialmente en el hecho de que la sustancia de los signos ya no era el sonido articulado, sino objetos. Sin embargo, la noción de "objeto" significante se complicó a la hora de ubicarla en una sociedad compleja como la actual, atravesada por los medios. Al fin, lo que Barthes (2005) encontró es que el significado de esos “objetos" sólo es accesible si es comunicado a través del lenguaje, es decir, si los objetos son asumidos por cierto discurso. De otro modo, estos sólo pueden ofrecer información marginal.

La semiología barthesiana, entonces, se reencuentra con la saussureana en el siguiente punto: la semiología más importante es la que se haga sobre el lenguaje. Así, pues, objetos como el vestido o la comida son significantes porque hay gente que habla de ello a diario. Cada vez que un sistema de comunicación está fundado en una sustancia que no es lenguaje, concluye Barthes (idem), habrá siempre la posibilidad de sustituir esa sustancia por lenguaje. ¿Por qué? Porque nuestra sociedad 
está fundada en la palabra, a pesar, dice él, de la invasión de las imágenes. La semiología de Barthes, pues, es tributaria del lenguaje como la de Saussure (1982). Según ellos, hay lenguaje en todos los lenguajes.

Al fin, la búsqueda propuesta por Barthes (2005), de hacer semiología de varios sistemas de significación, debe estar inspirada, dice, en la ambición de encontrar estructuras comunes en esos sistemas. Debe pretender, pues, una densa descripción del "imaginario humano", de todos los esquemas creados por el hombre para dar sentido a los objetos, concretos y abstractos, que conforman su realidad inmediata. Debe buscar comprender, en otras palabras, los mecanismos sociales para dar sentido. Para Barthes (idem) esto es hacer semiología. No aspirar a esto, en cambio, sería hacer sociología, es decir, quedarse con la idea de que los grupos sociales suponen hábitos de habla más o menos estereotipados, más o menos codificados, lo cual es cierto, pero describirlos sería el único propósito de su estudio.

Hacer semiología barthesiana, entonces, no es caer en el inventario gramatical de la lengua, sino aspirar a comprender los mecanismos de creación social de sentido que hay detrás de ella.

\section{EL FENÓMENO DEL DISCURSO \\ DESDE LA PERSPECTIVA BARTHESIANA}

Se ha de partir, entonces, de que el discurso, para Barthes (2001), es un fenómeno conformado por todas las formas sociales de decir algo sobre un tema $\mathrm{u}$ objeto de interés social, los cuales pueden partir de una realidad material o tangible o referir a concepciones abstractas. De cualquier forma, todo lo que se dice socialmente sobre ese objeto, al fin, se convierte en imaginario, es decir, conforma un imaginario, en el doble sentido ya explicado, puesto que está hecho o proporciona imágenes sobre ese concepto u objeto y puesto que está en el plano de lo no tangible (Barthes, 2005). El discurso, entonces, se convierte en una elaboración de pequeños lenguajes colectivos llenos de estereotipos (también ya en el sentido aclarado).

Los objetos que son motivo de discurso, ya sea que tengan una presencia material o abstracta en la vida cotidiana, cobran otra existencia distinta a través del discurso que se pronuncia sobre él. Sin esta inter- 
vención del lenguaje, la significación de su existencia puede ser resumida en una sintaxis rudimentaria y pobre. Sólo al ser convertido en un discurso de uso público, es decir, sólo al hablar de él con los demás, dicho objeto adquiere una verdadera consistencia social y semiológica. La forma en que se dice algo sobre algo, pues, proyecta el imaginario colectivo construido en torno a él, es decir, da salida a imágenes, estereotipos y toda la gama de elementos utópicos de los sujetos ${ }^{14}$.

La forma de decir algo, también, abre paso a las imágenes que les sirven a las personas para actuar con respecto a ese objeto. La forma en que se dice algo con respecto a algo, entonces, se convierte instantáneamente, dice Barthes (idem), en actos visibles con respecto a ese algo. ¿Por qué? Porque decir algo sobre algo de cierta forma es tomar ya una posición con respecto a ese algo y tomar posición es ya actuar. El discurso, entonces, trasciende de la esfera de lo dicho para abarcar mucho más que el lenguaje: el discurso abarca la vida social, en sí, de los sujetos, a partir del sentido que las cosas cotidianas adquieren para ellos.

Por otra parte, el análisis sobre el sentido que hay detrás de las formas del decir y el hacer con respecto a algo, debe partir del estudio del habla, es decir, del estudio del lenguaje puesto en acción por los sujetos. Sólo en los textos de los sujetos puede haber rastros del discurso, es decir, de lo que se dice socialmente sobre algo.

Cuando uno estudia el discurso sobre algo, el analista que se enfrenta a textos ajenos se proyecta en su análisis en nombre de la experiencia pasada. ¿Por qué? Porque uno reconoce las figuras con las que está hecho ese discurso, puesto que uno es parte del sentido socialmente creado al respecto del objeto del discurso. Al estar estereotipadas gran parte de las formas con las que se dice algo con respecto a un objeto, la interpretación que se hace en el análisis debe partir del repertorio común de estereotipos. Reconstruyendo el acervo de estereotipos reconocidos por el analista en el texto, se puede dar cuenta de la conformación del discurso.

El análisis propuesto por este estructuralista (idem), consistente en reconstruir el acervo de estereotipos, no basta para describir el discurso en sí, sino sólo para simularlo. Para describir el discurso en sí sería ne-

14 Elementos utópicos que no dejan de ser guía práctica del actuar real de los sujetos. 
cesario analizar todos los textos producidos en la historia social sobre un tema, cosa prácticamente imposible. Aspirar a analizar una muestra de los textos producidos sobre un tema, el resultado es la simulación del discurso, nunca el discurso mismo.

El resultado del análisis, entonces, no pretende describir el discurso en sí, sino el puesto en acción por un tipo de sujeto. El resultado, dice Barthes

es un discurso de un sujeto que dice yo, que por lo tanto está individualizado en el nivel de la enunciación; pero se trata de un discurso compuesto, simulado o un discurso montado (2005:242-243).

El que dice yo en el discurso es el yo de la descripción, es decir, el sujeto que aparece en esta simulación del discurso es también una simulación de sujeto.

El análisis del discurso propuesto por Barthes se presenta como una gramática, una descripción de los niveles de significación, de las unidades y de las reglas de combinación. En resumen, dice (idem), se presenta como una especie de sintaxis de la descripción de las formas. Sin embargo, su objetivo no es describir sino dar cuenta del sentido social detrás de esta gramática y de su conformación.

El análisis del discurso de Barthes se logra clasificando las unidades en clases formales (aquí llamadas tópicas). En el estudio del discurso amoroso hecho también por él (2001), las clases "seducción" o "engaño", por ejemplo, evitaron hablar de todas las seducciones y de todos los engaños. Luego de esta clasificación, lo que hay que encontrar, dice Barthes (2005), son "las reglas formales de transformación de las estructuras para comprender cómo los relatos se engendran a partir de las formas" (ibidem:47). Es decir, se trata de ubicar el sistema de funcionamiento lógico de la clasificación (aquí llamado unidad de sentido).

Se debe contemplar que el discurso es, por naturaleza, esencialmente fragmentado y discontinuo. Barthes (idem) lo describe como compuesto por episodios de lenguaje que "revolotean en la cabeza" del sujeto y que irrumpen en él bajo cualquier pretexto. Por eso en el texto el sujeto se salta de figura en figura. Por otra parte, la elección de esas figuras, y no otras, dan pie a comprender el funcionamiento social 
del discurso. El discurso del sujeto no puede convertirse en escritura sin abandonos y transformaciones, los cuales también tienen su sentido. El análisis debe comprender ese sentido también.

Al reconstruir, entonces, la simulación del discurso, este se desarrolla como la afirmación de una serie de sentidos. Barthes (idem), en realidad, los nombra como valores, es decir, cree que ese objeto perteneciente a lo imaginario del que trata el discurso está sostenido por una serie de valores sociales que le dan sentido. Todo lo que implique el "vivir juntos", afirma, se vuelve un problema de ética. Por tanto, todos los objetos imaginarios que refieren esa convivencia están sostenidos por valores.

\section{LA COMPOSICIÓN DEL DISCURSO}

DESDE LA PERSPECTIVA BARTHESIANA

Barthes (2001), pues, parte de concebir al discurso como un conjunto de textos convocados por una temática cualquiera. Así, el amor como tema, por ejemplo, convoca a un conjunto enorme de textos y conforma el discurso amoroso. Lo político, como tema, convoca, a su vez, otro conjunto de textos que conforman el discurso político, etcétera. Lo peculiar de cada discurso, sin embargo, dice él (idem), no es el tema en sí, sino el acervo de lugares comunes que conforman el tema, lugares comunes que posibilita que todos entiendan que cierto texto refiere a esa temática, o lugares comunes a los que uno recurre cuando quiere hablar sobre dicha temática. Dichos lugares comunes son nombrados por Barthes como "tópicas" (idem).

El discurso, entonces, no es equiparable a un texto, sino a un torrente de lugares comunes convocados por un tema, mismo que puede atravesar distintos textos y manifestarse en ellos. Por tanto, un texto difícilmente contendrá todo un discurso. Una carta de amor, por ejemplo, no contendrá en sí todo el discurso amoroso, pero sí evidencias de él. Un político al hablar, por ejemplo, no produce el discurso político, sino que produce un texto en el que puede haber evidencias del discurso político entre otros discursos, etcétera. Las evidencias manifiestas en el texto, de que está atravesado por un discurso, son los lugares comunes propios de una temática que se va citando al elaborar dicho texto. Cada lugar común 
referente a temáticas distintas refiere a discursos distintos. Un texto, pues, puede estar atravesado por muchos discursos. En un discurso pueden caber muchos textos. Discurso y texto, al fin, son distintos y son, pues, esos lugares comunes los que los vinculan.

Barthes (idem) entiende, entonces, el discurso a partir de tópicas. Estas pueden entenderse, también, como acepciones de la gran temática que convoca al discurso. Por ejemplo: del gran tema educación, que convoca al discurso educativo, una acepción puede ser el entender a la educación como una acción. Cuando uno dice "acto educativo" no sólo se esta echando mano a una muletilla educativa, sino a una forma de entender la educación: esta como acción. Si uno la entiende como acción, se sabe, entonces, que es ejecutada por un sujeto y que otro sujeto distinto es el que recibe el acto educativo y, así, ambos, actor y receptor, entablan una relación de poder activo-pasivo, misma que parte de la acción ejecutada, etcétera. De ese entendimiento surgen oraciones como "tengo el deber de educar" o "hay que educar a los niños". Al fin, estas expresiones tocan el lugar común de la ejecución de la educación como acción. Por tanto, la "tópica” sería la educación como acción, creando así una acepción de la educación.

Las tópicas no se encuentran en bruto en los textos, sino que asumen múltiples formas acorde a las apropiaciones de los hablantes. Esas formas están mediadas por escenarios, escenarios que Barthes (idem) nombra "figuras", que son, entonces, especificaciones de la acepción de un tema, es decir, especificaciones de la tópica. Por ejemplo, en el caso de la tópica "educación como acción”, una figura sería "el deber"; otra sería "el placer". Cada una especifica escenarios en el que la tópica funciona.

Ya a las concreciones textuales de estas figuras Barthes las nombra "actos". Así, por ejemplo, los de la figura "el deber" de la tópica "acción”, del discurso educativo, serían oraciones como "el gobierno tiene la obligación de educar", "los padres deben educar a sus hijos", "el deber de todo maestro es la educación", etcétera. Todas estas oraciones tienen en común el asumir la educación como una acción, pero también la tendencia a marcar dicho acto como una obligación. Otra figura de la tópica "educación como acción", podría ser la de "el placer", y esta se manifestaría en actos como: "el gozo de educar" o "educar con alegría”, etcétera. 
Un discurso, entonces, está compuesto por tópicas o lugares comunes, los cuales, a su vez, están compuestos por figuras, mismas que en el texto se manifiestan a través de actos. Si se ilustrara esta composición discursiva se obtendría un esquema así:

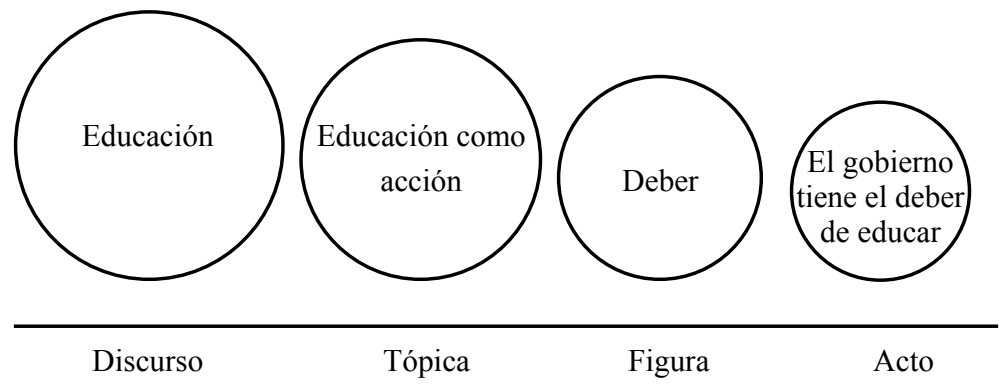

Un discurso posee innumerables tópicas. Las tópicas poseen innumerables figuras y las figuras se manifiestan en los textos en innumerables actos. Este es el modelo que Barthes (2001) ofrece para comprender al discurso y descomponerlo. Esta es, pues, su concepción del eje central de la comunicación.

\section{Bibliografía}

AUSTIN, J. L. (1988) Cómo hacer cosas con palabras, Barcelona: Paidós.

BARTHES, R. (1978) El placer del texto y lección inaugural, México: Siglo XXI.

BARTHES, R. (1980) S/Z, México: Siglo XXI.

- (2001) Fragmentos de un discurso amoroso, México: Siglo XXI.

- (2003) El sistema de la moda y otros escritos, Barcelona: Paidós.

- (2005) El grano de la voz. Entrevistas 1962-1980, Buenos Aires: Siglo XXI.

BenVeniste, E. (1971) Problemas de lingüistica general, México: Siglo XXI.

CORONA Berkin, S. (2000) "De los medios a los sujetos. Una trayectoria para abordar la comunicación desde los actores", en Orozco, G. (2000) Lo viejo y lo nuevo: investigar la comunicación en el siglo $X X I$, Madrid: Ediciones de la Torre. 
DUCROT O. y Shaeffer (1998) Nuevo diccionario enciclopédico de las ciencias del lenguaje, Madrid: Arrecife.

FUENTES Navarro, R. (2000) "Perspectivas socioculturales postdisciplinarias en la investigación de la comunicación”, en Orozco, G. (2000) Lo viejo y lo nuevo: investigar la comunicación en el siglo XXI, Madrid: Ediciones de la Torre.

MATTElART, A. y Mattelart, M. (1997) Historias de las teorías de la comunicación, Barcelona: Paidós.

PÉREZ Daniel, Myriam Rebeca (2004) El discurso y el saber amoroso: figuras y tópicas sobre el amor en epístolas juveniles zamoranas, tesis de maestría en comunicación, Guadalajara: Universidad de Guadalajara.

PÉREZ Martínez, Herón (1998) El texto (inédito).

- (2000) En pos del signo. Introducción a la semiótica, El Colegio de Michoacán, Zamora.

SAUSSURE, F. (1982) Curso de lingüística general, México: Nuevomar.

SCHMIDT (1978) Teoría del texto, México: Cátedra.

VAN DIJK, T. (2003) "La multidisciplinariedad del análisis crítico del discurso un alegato a favor de la diversidad", en Wodak, R. y Meyer, M. Métodos de análisis crítico del discurso, Barcelona: Gedisa.

VERON, E. (1999) Esto no es un libro, Barcelona: Gedisa. 